\title{
Keragaman Tumbuhan Paku Sebagai Pendukung Objek Wisata di Hutan Wisata Alam Oeluan, Timor Tengah Utara
}

\author{
Ite Morina Yostianti Tnunay ${ }^{\mathrm{a}}$, Dicky Frengky Hanas ${ }^{\mathrm{b}}$
}

${ }^{a}$ Fakultas Pertanian, Universitas Timor, Kefamenanu,TTU - NTT, Indonesia, email: ite tnunav@yahoo.co.id

${ }^{b}$ Fakultas Pertanian, Universitas Timor, Kefamenanu, TTU - NTT, Indonesia

\section{Article Info}

\section{Article history:}

Received 1 Juni 2020

Received in revised form 5 Juni 2020

Accepted 7 Juni 2020

\section{DOI:}

https://doi.org/10.32938/slk.v3i1.1045

\section{Abstrak}

Tumbuhan paku (Pteridophyta) sangat beragam dan mudah dijumpai termasuk di kawasan Hutan Wisata Alam Oeluan. Meskipun demikian, informasi ini masih terbatas padahal tumbuhan paku dapat menjadi potensi objek wisata di kawasan hutan wisata alam Oeluan. Penelitian ini bertujuan untuk mendata tumbuhan paku dan potensi pemanfaatannya selain sebagi objek wisata. Hasil penelitian menunjukkan bahwa terdapat 17 spesies tumbuhan paku, yang tergolong dalam 8 famili, yaitu Aspleniaceae, Davalliaceae, Nephrolepidaceae, Polypodiaceae, Psilotacea, Pteridaceae, Tectariaceae, dan Thelypteridaceae. Polypodiaceae merupakan famili yang paling dominan di kawasan Hutan Wisata Alam Oeluan.

\section{Keywords:}

Oeluan,

Pteridophyta,

Timor Tengah Utara

Tumbuhan Paku,

\section{Pendahuluan}

Tumbuhan paku termasuk dalam kelompok tumbuhan tingkat rendah. Seperti halnya lumut dan fungi, dalam perkembangbiaknya secara generatif tumbuhan paku menggunakan spora hal ini yang membedakannya dari kelompok tumbuhan tingkat tinggi yang berkembangbiak menggunakan biji. Namun demikian, tumbuhan paku sudah termasuk tumbuhan berkormus atau tumbuhan dengan sistem pembuluh sejati yang mana bagian-bagian utama sebagai tumbuhan sudah dapat dibedakan yaitu akar, batang dan daun (Tjitrosoepomo, 2009).

Tumbuhan paku sangat beragam, apabila ditinjau dari aspek habitus ataupun morfologinya. Ada jenis-jenis tumbuhan paku dengan struktur yang sederhana berukuran kecil dengan daun-daun yang kecil ada pula yang besar dengan ukuran daun yang panjang dan lebar dengan struktur yang rumit. Berdasarkan cara hidupnya ada jenis-jenis paku yang hidup di atas tanah (terestrial), ada yang hidupnya menumpang pada tumbuhan lain (epifit), dan ada paku air (higrofit). Keberadaan tumbuhan paku yang beragam ini dapat dijumpai dari daerah beriklim tropis maupun daerah subtropis.

Di Indonesia sampai dengan tahun 2014, tumbuhan paku yang telah dilaporkan teridentifikasi sejumlah 2.197 jenis atau sekitar $22 \%$ dari total keseluruhan tumbuhan paku yang teridentifikasi di dunia (LIPI, 2014; Bappenas 2016). Hal ini menunjukan bahwa keragaman tumbuhan paku di Indonesia sangat menyumbang kontribusi yang tinggi terhadap tingkat keanekaragaman tumbuhan paku dunia. Dengan keragaman tipe ekosistem dan kerberadaan ekosistem yang khas dan unik yang tersebar pada ribuan pulau, sangat memungkinkan tingginya keragaman tumbuhan paku di Indonesia.

Timor Tengah Utara (TTU) sebagai bagian dari propinsi Nusa Tenggara Timur (NTT) di wilayah Indonesia bagian tengah, memiliki tipe ekosistem dan topografi wailayah yang khas. Walaupun dikenal sebagai daerah yang kering dengan curah hujan yang rendah, di Kabupaten TTU terdapat beberapa kawasan dengan hutan yang hijau dan sejuk serta menjadi kawasan konservasi salah satunya yaitu kawasan hutan wisata alam Oeluan yang berada pada wilayah administrastif Desa Bijeli Kecamatan Noemuti.

Hutan wisata alam Oeluan ditumbuhi berbagai jenis tumbuhan perdu, semak dan pepohonan yang tingginya hingga puluhan meter. Dalam kawasan hutan wisata ini terdapat aliran air dan sungai yang menjadikan lokasi ini lembab dan sejuk sehingga juga mendukung pertumbuhan kelompok tumbuhan tingkat rendah seperti lumut dan tumbuhan paku (Pteridophyta). Untuk mendukung pemanfaatan kawasan ini sebagai hutan wisata alam perlu dilakukan pendataan keragaman tumbuhan paku sebagai langkah awal dalam mengenal potensi keberadaan tumbuhan paku yang dapat dijadikan sebagai bagian dari objek wisata dalam kawasan hutan wisata alam Oeluan.

\section{Metode}

Penelitian ini dilaksanakan pada bulan Maret sampai April 2020 di Kawasan Hutan Wisata Alam Oeluan Kecamatan Noemuti Kabupaten TTU Provinsi NTT. Koleksi spesimen tumbuhan paku dilakukan menggunakan metode eksplorasi dengan menjelajahi spot-spot yang ditumbuhi tumbuhan paku. Spesimen tumbuhan paku yang dikoleksi selanjutnya diidentifikasi menggunakan panduan identifikasi tumbuhan paku, yaitu Fern of Malaysian Rain Forest (Yusuf, 2010) dan Flora Indonesiana Fern of Bali (Adjie \& Lestari, 2011). Data tumbuhan paku yang diperoleh dianalisis dengan metode deskriptif kualitatif berdasarkan ciri morfologi. Validasi nama dilakukan pada situs https://www.plantlist.org.

\section{Hasil dan Pembahasan}

3.1. Keragaman tumbuhan (Pteridophyta) di Hutan Wisata Alam Oeluan
Hasil eksplorasi menunjukkan terdapat 17 spesies tumbuhan paku dengan morfologi yang beragam. Keseluruhan spesies diklasifikasikan ke dalam 8 famili (Tabel 1). Polypodiaceae memiliki anggota yang paling banyak, yaitu 4 genus dan 5 spesies. Polypodiaceae merupakan suku tumbuhan paku yang paling banyak ditemukan diberbagai tempat termasuk sebagian besar kepulauan di Indonesia (Holtum, 1968; Boonked et al., 2008).

Tabel 1. Keragaman Tumbuhan Paku (Pteridophyta) di Hutan Wisata Alam Oeluan

\begin{tabular}{|c|c|c|c|}
\hline No & Famili & Genus & Spesies \\
\hline 1. & Aspleniaceae & Asplenium & Asplenium nidus $\mathrm{L}$. \\
\hline 2. & Davalliaceae & Davallia & Davallia sp. \\
\hline 3. & Nephrolepidaceae & Nephrolepis & $\begin{array}{l}\text { N. biserrata }(\mathrm{Sw} .) \text { Schott } \\
\text { N. cordifolia }(\mathrm{L} .) \text { C. Presl }\end{array}$ \\
\hline 4. & Polypodiaceae & $\begin{array}{l}\text { Drynaria } \\
\text { Phymatosorus }\end{array}$ & $\begin{array}{l}\text { D. quercifolia (L.) J. Sm } \\
P . \text { membranifolius (R. Br.) } \\
\text { Tindale }\end{array}$ \\
\hline & & $\begin{array}{l}\text { Platycerium } \\
\text { Pyrrosia }\end{array}$ & $\begin{array}{l}\text { P. bifurcatum (Cav.) C. Chr. } \\
\text { P. lanceolata (L.) Farw. } \\
\text { P. longifolia (Burm. F.) C.V. } \\
\text { Morton }\end{array}$ \\
\hline 5. & Psilotacea & Psilotum & P. complanatum $\mathrm{Sw}$. \\
\hline 6. & Pteridaceae & $\begin{array}{l}\text { Adiantum } \\
\text { Pteris }\end{array}$ & $\begin{array}{l}\text { A. diaphanum Blume } \\
\text { P. vitata } \mathrm{L} \text {. } \\
\text { P. multifida } \text { Poir. }\end{array}$ \\
\hline & & Vittaria & $V$. ensiformis $\mathrm{Sw}$. \\
\hline 7. & Tectariaceae & Pleocnemia & P. conjugata (Blume) C. Presl \\
\hline 8. & Thelypteridacea & Cyclosorus & $\begin{array}{l}\text { C. parasiticus (L.) Farw. } \\
\text { C. } \operatorname{aridus} \text { (D. Don) Tagawa }\end{array}$ \\
\hline
\end{tabular}

\subsection{Deskripsi Tumbuhan Paku di Hutan Wisata Alam Oeluan}

Tumbuhan paku (Pteridophyta) yang teridentifikasi di Hutan Wisata Alam Oeluan memiliki tingkat keberagaman jenis, habitus, bentuk serta ukuran yang memperkaya tingkat biodiversitas tumbuhan sekaligus memperindah kawasan wisata ini sebagai salah satu daya tarik wisata (Gambar 1).

Asplenium nidus L. Paku epifit berakar serabut berawarna coklat kehitaman dan rimpangnya tumbuh menempel pada batang pohon inang, ental/daunnya berupa lembaran yang tumbuh berlapis atau bergerombol dan menjuntai hingga $100 \mathrm{~cm}$ dan lebar dapat melebihi $10 \mathrm{~cm}$, berwarna hijau dengan ujung meruncing, tepi daun rata agak bergelombang, tulang daun menyirip. Sorus terdapat pada sebelah bawah lembaran daun, tersusun searah urat daun, sporangium berwarna coklat (Gambar 1a).

Davallia sp. Paku terestrial, tumbuh disekitar perakaran pohon, rimpang/rhizome berukuran pendek berwarna coklat kehitaman, tangkai daun berwarna hitam, tumbuh tegak dari rimpang, tulang daun menjari berwarna hijau pada permukaan atas dan berwarna hitam pada permukaan sebelah bawah, memiliki tipe daun tunggal, helaian daun berwarna hijau yang tumbuh mengikuti arah pertulangan daun, ujung daun pada setiap pertulangan daun meruncing, permukaan atas daun berwarna hijau mengkilap, permukaan bawah daun berwarna hijau muda, tepi daun berbagi, sorus berwarna coklat, terletak pada permukaan sebelah bawah daun fertil, tersusun rapi pada seluruh bagian tepi daun (Gambar 1b).

Nephrolepis biserrata (Sw.) Schott Terna epifit atau setengah epifit. Hidup merumpun, akarnya berwarna coklat tua. Rimpangnya tipis, menyerupai 
akar. Dari rimpangnya tumbuh ental yang panjangnya mencapai 1,5 m. Batang berwarna hijau kecoklatan dan tumbuh tegak. Mempunyai daun majemuk dengan anak-anak daun menyirip berwarna hijau terang, tersusun rapat dan tersebar di sepanjang batang, daun dibagian atas lebih kecil daripada daun yang terletak dibagian bawah. Ujung daun runcing, tepinya bergelombang, pangkalnya berlekuk. Daun yang masih muda menggulung. Sporangium terdapat dibagian permukaan bawah daun yang terletak sejajar searah tulang daun dari pangkal kearah ujung daun, berbentuk bulat dengan diameter sekitar $0,5 \mathrm{~mm}$ dan berwarna coklat (Gambar 1c).

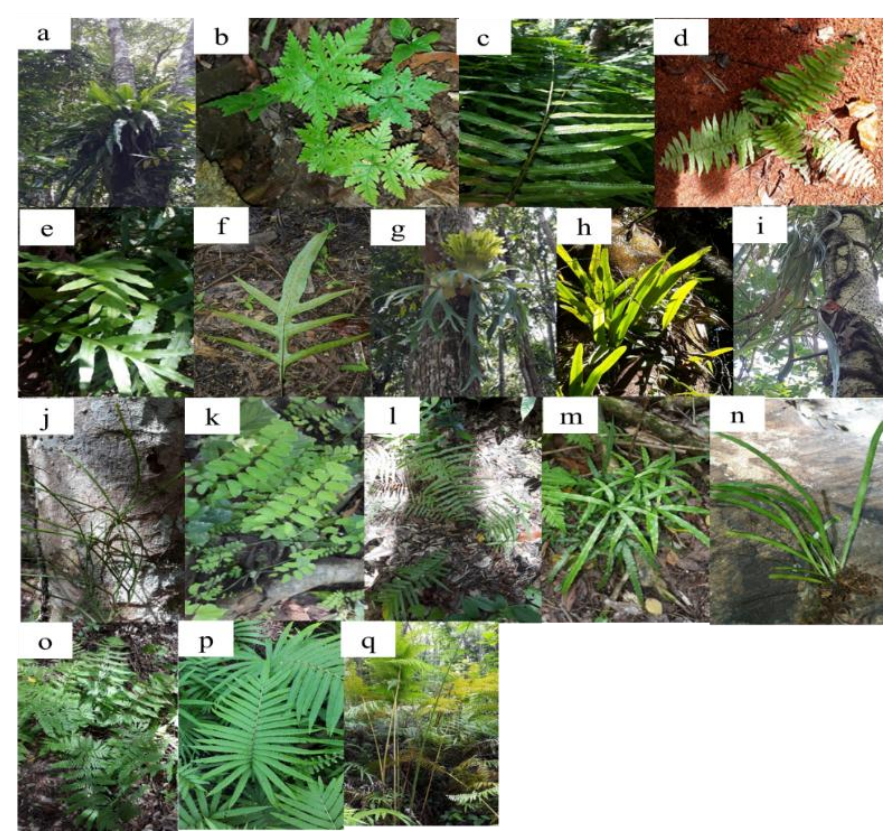

Gambar 1. Keragaman ciri morfologi tumbuhan paku (Pterydophyta) di Hutan Wisata Alam Oeluan: a. Asplenium nidus L.; b. Davalliaceae sp.; c. Nephrolepis biserrata (Sw.) Schott, d. Nephrolepis cordifolia (L.) C. Presl, e. Drynaria quercifolia (L.) J. Sm, f. Phymatosorus membranifolius (R. Br.) Tindale, g. Platycerium bifurcatum (Cav.) C. Chr., h. Pyrrosia lanceolata (L.) Farw., i. Pyrrosia longifolia (Burm. F.) C.V. Morton, j. Psilotum complanatum Sw, k. Adiantum diaphanum Blume, 1. Pteris vitata L., m. Pteris multifida Poir., n. Vittaria ensiformis Sw., o. Pleocnemia conjugata (Blume) C. Presl, $\mathrm{p}$. Cyclosorus parasiticus (L.) Farw., q. Cyclosorus aridus (D. Don) Tagawa

Nephrolepis cordifolia (L.) C. Presl. Kelompok paku terrestrial, dengan tangkai daun (rachis dan stipe) berwarna coklat yang tumbuh tegak. Daun majemuk berwarna hijau, permukaan atas beralur duduk daun berseling, tepi daun rata agak bergelombang, ujung anak daun meruncing, susunan daun lebih panjang pada bagian pangkal tangkai daun dan lebih pendek kearah ujung daun dan meruncing kearah ujung tangkai daun. Daun steril dan daun fertil berukuran hampir sama. Sorus terletak pada permukaan sebelah bawah daun, berwarna coklat berbentuk bulat tersusun rapi pada kedua sisi tepi daun dari pangkal hingga ujung anak daun (pinna) (Gambar 1d).

Drynaria quercifolia (L.) J. Sm. Tumbuhan paku epifit yang menempel pada pohon inang, rimpang/rhizome berwarna coklat, berakar serabut, tangkai dau berwarna hitam. Berdaun tunggal, menyirip, tulang daun kaku dan keras, ujung daun meruncing, permukaan daun halus dan tepi daun rata agak bergelombang, warna daun hijau. Memiliki daun penyangga berwarna hijau yang terlihat membungkus bagian akar dan rhizome yang menempel pada batang tanaman inang. Sorus berbentuk titik-titik bulat berwarna coklat yang tersebar pada permukaan bawah daun (Gambar 1e).

Phymatosorus membranifolius (R. Br.) Tindale. Paku epifit, rhizome berwarna coklat, tangkai daun berwarna hitam tumbuh tegak, berdaun tunggal tipe daun menyirip, daun steril dan daun fertil berukuran hampir sama, sorus terletak seperti titik-titik berbentuk bulat pada permukaan bawah daun berwarna kuning kecoklatan (Gambar 1f).

Platycerium bifurcatum (Cav.) C. Chr. Kelompok paku epifit dengan akar dan rimpang/rhizome yang menempel pada pohon inang. Dari rimpang tumbuh ental/daun yang terdiri dari daun steril dan daun fertil. Daun steril atau daun penyokong seperti perisai menutupi akar dan rhizome dan berwarna hijau kekuningan sedangkan daun fertil agak tebal tumbuh menjuntai dan bercabang menggarpu berwarna hijau, tepi daun rata dengan ujung yang tumpul atau meruncing. Sorus dengan sporangium berwarna coklat tersebar pada bagian ujung sebelah bawah daun (Gambar $1 \mathrm{~g}$ ).

Pyrrosia lanceolata (L.) Farw. Kelompok paku epifit yang tumbuh menjalar pada permukaan batang pohon inang. Akar dan rhizome berwarna coklat tumbuh searah pertumbuhan batang tanaman inang. Ptiolus atau tangkai daun berwarna hijau kecoklatan. Ental/daun tunggal agak tebal; tumbuh tegak hingga $20 \mathrm{~cm}$; tepi daunnya rata berwarna hijau, tulang daun berwarna hijau, daun steril lebih pendek dari daun steril dengan ujung membulat atau tumpul sedangkan daun fertil lebih panjang dari daun steril dengan ujung meruncing; sorus terletak pada permukaan sebelah bawah ujung ental/daun, berwarna coklat; sporangium berbentuk bulat bergerombol sepanjang 2-5 $\mathrm{cm}$ dari ujung daun kearah pangkal, tersusun rapi dan rapat pada kedua sisi tulang daun (Gambar 1h).

Pyrrosia longifolia (Burm. F.) C.V. Morton. Termasuk kelompok paku epifit yang tumbuh menjalar dan meliliti searah pertumbuhan batang pohon inang dengan akar dan rhizome berwarna coklat; tangkai daun berwarna coklat kehiaman; ental atau daun tunggal agak tebal tumbuh menjuntai hingga 30-50 $\mathrm{cm}$, tepi daun rata berwarna hijau, daun steril berukuran lebih pendek dengan ujung membulat atau runcing sedangkan daun fertil berukuran lebih panjang dengan ujung agak ramping dan meruncing. Sorus terletak pada permukaan sebelah bawah ujung ental/daun, berwarna coklat; sporangium berbentuk bulat bergerombol hingga $2 / 3$ bagian dari ujung daun kearah pangkal, tersusun rapat pada kedua sisi tulang daun (Gambar 1i).

Psilotum complanatum Sw. Paku epifit pada pohon inang, berakar serabut, seluruh bagian tubuh tersusun atas tangkai seperti kawat yang bentuknya bersegi, bercabang-cabang dengan pola dikotom dan berwarna hijau. Daun berukuran kecil seperti sisik berwarna hijau kekuningan. Sporangium tedapat dalam sinangium yang berbentuk bulat berwarna hijau kekuningan atau kuning terletak tersebar pada tiap ketiak daun (Gambar 1j).

Adiantum diaphanum Blume. Paku terrestrial berakar serabut, rimpang menajalar, tangkai ental berbentuk seperti kawat berwarna hitam mengkilap seperti warna rambut; berdaun majemuk, duduk daun bersilang berhadapan, bentuknya membulat seperti kipas tapi tidak simetris, helaian daun berwarna hijau agak tipis dengan permukaan daun berambut halus, tulang daun menyirip, pinggiran ujung daun berlekuk dan bergelombang, sorus terletak pada ujung lekukan tepi daun (Gambar 1k).

Pteris vitata L. Paku terrestrial, perawakan herba, berakar serabut degan rimpang/rhizome menjalar berwarna coklat, tangkai tumbuh tegak. Berdaun majemuk menyirip berwarna hijau tersusun berseling disepanjang tangkai, anak daun memanjang dengan ujung meruncing, tepi daun rata serta daun steril dan fertil berukuran 11ertil sama. Sorus terdapat pada permukaan sebelah bawah daun, berwarna coklat dan tersusun pada bagian tepi kedua sisi anak daun dari pangkal hingga ujung (Gambar 11).

Pteris multifida Poir. Tumbuhan paku dengan rimpang/rhizome yang pendek berwarna coklat, berakar serabut, tipe daun majemuk menjari tumbuh tegak, berwarna hijau, lemabaran daun (pinna) memanjang, tepi daun rata agak bergelombang. Sorus terletak pada sebelah bawah daun fertil tersusun rapi pada seluruh tepi daun berwarna putih kebuan (Gambar 1m)

Vittaria ensiformis Sw. Paku epifit, berakar serabut, rimpang/rhizome berukuran pendek berwarna coklat tua, daun monomorfik, tipe daun tunggal, memanjang, berwarna hijau, permukaan daun licin mengkilap, tepi daun rata, ujung daun membulat. Individu dengan sorus tidak ditemukan saat pengamaatan (Gambar 1n)

Pleocnemia conjugata (Blume) C. Presl. Paku terrestrial, berakar serabut, tangkai tumbuh tegak dari rhizome, tipe daun majemuk berwarna hijau, tulang daun menyirip duduk daun berselang-seling, tepi anak daun bercangap, ujung daun membulat, anak daun dekat pangkal lebih panjang dan lebih pendek kearah ujung daun, sorus terletak pada permukaan sebelah bawah daun fertil, sporangium berwarna coklat berbentuk bulat tersusun zig-zag mengikuti alur tepi anak daun (pinna) dari pangkal hingga ujung daun (Gambar 1o).

Cyclosorus parasiticus (L.) Farw. Paku terestrial, daun berwarna hijau dengan tipe daun majemuk menyirip, duduk daun berselang-seling, tepi daun bergerigi dengan ujung daun meruncing, daun steril dan daun fertil memiliki ukuran yang hampir sama, sorus berada pada permukaan sebelah bawah daun fertil, sporangium berwarna coklat berbentuk bulat tersusun zig-zag mengikuti alur tepi anak daun (pinna) dari pangkal hingga ujung daun (Gambar 1p).

Cyclosorus aridus (D. Don) Tagawa. Paku terestrial, tumbuh bergerombol, batang berwarna hijau muda, tumbuh tegak dapat mencapai sekitar 2-3 m, permukaan batang berambut kasar, tipe daun majemuk berwarna hijau, tulang daun menyirip, duduk daun berselang seling, tepi daun bercangap, ujung daun meruncing, anak daun dekat pangkal lebih panjang dan lebih pendek kearah ujung daun, sorus terletak pada permukaan sebelah bawah daun fertil, sporangium berwarna coklat berbentuk bulat tersusun zig-zag mengikuti alur tepi anak daun (pinna) dari pangkal hingga ujung daun (Gambar 1q).

\subsection{Potensi Pemanfaatan Tumbuhan Paku di Taman Wisata Alam Oeluan}

Keberadaan tumbuhan sebagai bagian dari suatu ekosistem sangat mempengaruhi kehidupan makluk hidup yang ada di sekitarnya. Tumbuhan paku yang terdapat di Hutan Wisata Alam Oeluan memiliki manfaat secara ekologis yang belum diketahui dan dimanfaatkan dengan baik. Adapan rekomendasi potensi dari tumbuhan paku yang ada di Hutan Wisata Alam Oeluan tertera pada Tabel 2 berikut.

Tabel 2. Potensi Pemanfaatan Tumbuhan Paku di Hutan Wisata Alam Oeluan

\begin{tabular}{lcl}
\hline No. & \multicolumn{1}{c}{ Spesies } & \multicolumn{1}{c}{ Pemanfaatan } \\
\hline 1. & Asplenium nidus L. & $\begin{array}{l}\text { Obat antimalaria, menurunkan demam, obat } \\
\text { kaki gajah, obat penenang, pembesaran limfa, } \\
\text { penyubur rambut (Hartini, 2006; Goswami, }\end{array}$
\end{tabular}
penyubur rambut (Hartini, 2006; Goswami, 2016) 
2. Davallia $\mathrm{sp}$

Tanaman hias; beberapa spesies dari famili ini memiliki potensi anti kanker dalam pengobatan tradisinal china dan korea (Baskaran et al., 2018)

3. Nephrolepis biserrata Tanaman hias, sumber antioksidan, (Sw.) Schott menyembuhkan luka (Goswami, 2016; Kormin et al., 2016; Baskaran et al., 2018)

4. Nephrolepis cordifolia Tanaman hias; anti inflamasi, anti mikroba, (L.) C. Presl menghentikan pendarahan pada luka, anti diabetes (Baskaran et al., 2018)

5. Drynaria quercifolia Tanaman hias, sumber antioksidan, obat anti (L.) J. Sm kanker, obat anti inflamasi, obat maag, sakit kepala, Penyembuhan luka, sakit pinggang, demam, batuk (Hovenkamp at al., 1998; Goswani, 2016; Baskaran et al., 2018)

6. Phymatosorum Obat gonorrhea, radang tenggorokan, asma, membranifolius (R. melancarkan pencernaan, penyembuhan luka, Br.) Tindale antimual, keseleo, patah tulang (Goswami, 2016)

7. Platycerium Tanaman hias

bifurcatum (Cav.) C.

Chr.

8. Pyrrosia lanceolata Obat sakit kepala, disentri, penyakit kulit (L.) Farw. $\quad$ karena iritasi, batuk dan radang tenggorokan (Hartini, 2006; Benjamin \& Manickam, 2007; Goswami, 2016).

9. Pyrrosia longifolia Tanaman hias

(Burm. F.) C.V. Morton

\begin{tabular}{lll}
\hline 10. & $\begin{array}{l}\text { Psilotum } \\
\text { complanatum Sw. }\end{array}$ & Tanaman hias \\
\hline 11. & $\begin{array}{l}\text { Adiantum diaphanum } \\
\text { Blume }\end{array}$ & Tanaman hias \\
\hline 12. & Pteris vitata L. & $\begin{array}{l}\text { Tanaman hias, sumber antioksidan, } \\
\text { antimikroba, antivirus (Ulum \& Setyati, } \\
\text { 2015; Baskaran et al, 2018) }\end{array}$ \\
\hline 13. & Pteris multifida Poir. & $\begin{array}{l}\text { Tanaman hias; obat disentri, obat batuk, anti } \\
\text { kanker, anti mikroba (Wang \& Zhang, 2008; } \\
\text { Goswani, 2016; Baskaran } \text { et al., 2018) }\end{array}$ \\
\hline 14. & $\begin{array}{l}\text { Vittaria ensiformis } \\
\text { Sw. }\end{array}$ & $\begin{array}{l}\text { Tanaman hias; sumber antioksidan (Kormin } \\
\text { et al., 2016) }\end{array}$ \\
\hline 15. & $\begin{array}{l}\text { Pleocnemia conjugata } \\
\text { (Blume) C. Presl }\end{array}$ & Tanaman hias \\
\hline 16. & $\begin{array}{l}\text { Cyclosorus parasiticus } \\
\text { (L.) Farw. }\end{array}$ & Tanaman hias; Anti kanker (Wei et al., 2013) \\
\hline 17. & $\begin{array}{l}\text { Cyclosorus aridus (D. } \\
\text { Don) Tagawa }\end{array}$ & Tanaman hias \\
\hline
\end{tabular}

Keberadaan tumbuhan paku (Pteridohyta) sangat beranekaragam. Mulai dari ragam jenis atau spesies, ragam ukuran, ragam karakter morfologi, baik ragam habitatnya maupun ragam pemanfaatanya. Di Indonesia telah diketahui lebih dari dua ribuan jenis tumbuhan paku yang tersebar pada ribuan pulau baik pada kawasan yang dilindungi maupun kawasan liar. Bentuk, ukuran, warna maupun corak yang beragam dan unik membuat tumbuhan paku memiliki daya tarik untuk di pelajari, diteliti maupun dimanfaatkan. Ada banyak penelitian yang melaporkan tumbuhan paku sudah dimanfaatkan sebagai sumber bahan belajar, sumber pangan dan obat-obatan, sebagai tanaman hias maupun sebagai objek daya tarik wisata. Di Kebun Raya Eka Karya Bedugul Bali tumbuhan paku ditata pada area atau spot khusus yang dijadikan salah satu daya tarik objek wisata sebagai wahana edukasi dan konservasi (Darma, 2012)

Tumbuhan paku yang telah terindentifikasi di Hutan Wisata Alam Oeluan memiliki keragaman jenis, warna, bentuk, ukuran yang unik dan berpotensi dijadikan sebagai salah satu objek daya tarik wisata. Oleh sebab itu, perlu adanya langkah selanjutnya dalam pemanfaatan dan pengeloaan tumbuhan paku yang ada di hutan wisata ini sabagai salah satu daya tarik wisata dalam rangka wisata edukasi dan konservasi.

\section{Simpulan}

Hasil eksplorasi di Hutan Wisata Alam menunjukkan bahwa terdapat 17 spesies tumbuhan paku, yang tergolong dalam 8 famili, yaitu Aspleniaceae, Davalliaceae, Nephrolepidaceae, Polypodiaceae, Psilotacea, Pteridaceae, Tectariaceae, dan Thelypteridaceae. Polypodiaceae merupakan famili yang paling dominan di kawasan Hutan Wisata Alam Oeluan. Tumbuhan paku yang ada sangat berpotensi sebagai tanaman hias dan juga dapat untuk dimafaatkan sebagai tanaman berkhasiat obat. Keberagaman dan keindahan tanaman paku di kawasan Hutan Wisata Alam Oeluan dapat dijadikan sebagai salah satu objek daya tarik wisata bagi kawasan hutan wisata ini.

\section{Pustaka}

Adjie, B., Lestari, WS. 2011. Flora Indonesia, Ferns of Bali. Bali Botanical Garden, Indonesia Institute of Sciences. Baturiti.

BAPPENAS, KLH dan LIPI. 2016. Indonesia Biodiversity Strategy and Action Plan (IBSAP) 2015-2020. Kementerian Perencanaan Pembangunan Nasional.

Baskaran, X., Antony-varuvei G., Shou-zhou Z., Shi-xiu F. \& Wen-bo L. 2018. A review of the use of pteridophytes for treating human ailments. Zheijang University- Science B (Biomedicine \& Biotechnology) 19(2): 85-119.

Benjamin, A. \& Manickam, VS. 2007. Medicinal pteridohytes from the Western Ghats. Indian Journal of Traditional Knowledge 6: 611-618.

Boonked, T., Chantanaorrapint, S., Kwaiphan, W. 2008. Pterydophte Diversity in the Tropical Lowland Rainforest of Khao Nan National Park, Nakhon Si Thammarat Province, Thailand. The Nat History Journal Chulalongkorn Univ 8 (2):83-97.

Darma, IDP. 2012. Kebun Raya “Eka Karya”' Bali, Konservasi Dan Budaya dalam Harmoni. Buletin Udayana Mengabdi. UPT Balai Konservasi Tumbuhan Kebun Raya Eka Karya LIPI. Tabanan.

Goswami, HK., Sen, K., Mukhopadhyaay, R. 2016. Pteridophytes: evolutionary boon as medicinal plants. Plant Genetic Resources: Characterization and Utilization 14 (4): 328-355.

Hartini, S. 2006. Tumbuhan Paku Di Cagar Alam Sago Malintang, Sumatera Barat dan Aklimatisasinya di Kebun Raya Bogor. Biodiversitas, 7(3): (230236).

Holtum, RE. 1966. A Revised Flora of Malaya: Vol. II, Ferns of Malaya. Singapura. Goverment Printing Office.

Hovenkamp, PH., M.T.M.Bosman, E. Hennipma, H.P.Nootebom, G. RodlLinder, and M.C.Roos. 1998. Polypodiaceae in Flora Malesiana, Vol.3 series II-Ferns and Fern Allies. Leiden: Rijksh Herbarium.

Kormin, F., Muhammad K \& Ade Chandra I. 2016. Microwave Assisted Extraction; Phytochemical Evaluation of Malaysian Palm Oil Trunk Epiphytes Ferns. International Journal of Pharmacy and Pharmaceutical Science, 8(4):174 -180.

LIPI (Lembaga Ilmu Pengetahuan Indonesia). 2014. Kekinian Keanekaragaman Hayati Indonesia. LIPI Press. Bogor.

Tjitrosoepomo, G. 2009. Taksonomi Tumbuhan (Schizophyta, Thallophyta, Bryophyta, Pteridophyta). Yogyakarta: Gajah Mada Press.

Ulum, F.B. \& Setyati, D. 2015. Pteridophytes of Alas Purwo National Park and Their Medicinal Potency. Proceeding The 1st IBSC: Towards The Extended Use Of Basic Science For Enhancing Health, Environment, Energy and Biotechnology.

Wang, G \& Zhang, L.M. 2008. Study of the Extract from Pteris multifida Poir. On Antitumor Activity. Hebeisheng Kexueyuan Xuebao, 25:52-54 (in Chinese).

Wei, H., Xuenong Z., Guanghua Wu., Xian Y., Songwei P., Yanyan W \& Jinlan R. 2013. Chalcone Derivatives from the Fern Cyclocorus Parasiticus and Their Anti-proliferative Activity. Food and Chemical Toxicology, 60 (147152)

Yusuf, UK. 2010. Ferns of Malaysian Rain Forest, A Journey Through The Fern World. Universiti Putra Malaysia Press. Serdang. 